\title{
Soluble mediators of immune significance in sera of leprosy patients
}

\author{
Amit Dubey ${ }^{\mathrm{a}}$, Ritu Gaur ${ }^{\mathrm{a}}$, Nidhi Arela ${ }^{\mathrm{a}}$, Vandana Singh ${ }^{\mathrm{a}}$, \\ Mamta Arora ${ }^{b}$, Harish Sagar ${ }^{b}$, Raj Kamal ${ }^{b}$, Mohan Natarajan ${ }^{c}, \dagger$, \\ Sameer S. Bhagyawant ${ }^{\mathrm{d}}$, Shripad A. Patil ${ }^{\mathrm{e}}$ \& \\ Keshar Kunja Mohanty ${ }^{\mathrm{a}}$ \\ ammunology Division, National JALMA Institute for Leprosy and Other \\ Mycobacterial Diseases, Agra-282004, Tajganj, India; \\ ORCID: https://orcid.org/0000-0001-7527-4864 \\ ${ }^{\mathrm{b}}$ Clinical Division National JALMA Institute for Leprosy and Other \\ Mycobacterial Diseases, Tajganj, Agra-282004, India \\ ${ }^{\mathrm{c}}$ Histopathology Division National JALMA Institute for Leprosy and Other \\ Mycobacterial Diseases, Tajganj, Agra-282004, India \\ d School of Biotechnology, Jiwaji University,, Gwalior-474001, India \\ e National JALMA Institute for Leprosy and Other Mycobacterial Diseases, \\ Agra-282004, Tajganj, India
}

Submitted 21 July 2020; Accepted 21 September 2020

\begin{abstract}
Summary
Background: The disease leprosy is categorized by a wide spectrum of clinical forms imposed by the patient's immune responses to the organism, Mycobacterium leprae. Soluble receptors and soluble mediators are important for regulation of immune responses.

Objectives: As leprosy reactions are known immune inflammatory reactions during the disease process, the aim of the study was to screen nitrite, IL-6 cytokine and sTLR2 in sera samples to identify circulating biomarkers associated with leprosy and T1R and T2R among patients recruited from the Northern part of India.

Methods: Leprosy patients recruited in our Institute were included in this study. We analysed the level of nitrite, soluble TLR2 and IL-6 in sera of leprosy patients, healthy controls and healthy household contacts by colorimetric assay and ELISA respectively. Results: The level of serum nitrite was observed to be higher in tuberculoid leprosy patients compared to lepromatous leprosy patients $(p=0.006)$. The level was also higher in healthy contacts of leprosy patients compared to lepromatous leprosy patients $(p=0.008)$. The sTLR 2 level was significantly higher in healthy controls than leprosy
\end{abstract}

\footnotetext{
Correspondence to: Dr. Keshar Kunja Mohanty, Scientist F, National JALMA Institute for Leprosy and Other Mycobacterial Diseases, Tajganj, Agra-282004, India (e-mail: keshar63@yahoo.com; mohanty.kk@icmr.gov.in)

The level of Soluble TLR2, Nitrites and IL-6 is different in sera of leprosy patients and healthy controls, having potential for biomarkers.

$\dagger$ Present address: National Institute for Research in Tuberculosis, No 1 Sathiyamoorthy Road, Chetput, Chennai600031, Tamil Nadu, India.
} 
patients $(p=0.002)$ and their healthy contacts $(p=0.001)$. The level of IL-6 in serum was significantly higher in leprosy patients than in healthy controls $(p=0.001)$.

Conclusion: Nitrite, IL- 6 cytokine and sTLR2 are shown to be potential circulating biomarkers associated with leprosy among patients recruited in Northern India.

Keywords: Leprosy, reactions, M. leprae, soluble toll like receptor 2, nitric oxides

\section{Introduction}

Leprosy is a granulomatous disease caused by infection with the intracellular bacterium, Mycobacterium leprae that mainly affects skin and peripheral nerves. ${ }^{1}$ Leprosy displays an array of clinical presentations from the tuberculoid pole to the lepromatous pole, through borderline forms, categorized by Ridley and Jopling, based on clinical and histopathological findings, and correlated with the host immune response to the pathogen.

Leprosy patients often experience inflammatory episodes known as reactions, which lead to rapid loss of sensation, nerve damage and deformity. ${ }^{3}$ Type 1 or Reversal reaction (T1R) is known to occur in the borderline group of patients (i.e., BL, BB, and BT) while multibacillary patients (BL and LL), experience erythema nodosum leprosum (ENL) or Type 2 reaction (T2R). ${ }^{4}$ Increased levels of proinflammatory cytokines in peripheral blood were noted in reversal reactions which were lowered with corticosteroid treatment. ${ }^{5,6}$ IL-6 has been shown to be a promising biomarker for both Type 1 reactions ${ }^{7}$ and Type 2/ENL reactions. ${ }^{89}$ Further, higher levels of IL-6 in mast cells were also noted to be associated with reversal reaction in leprosy. ${ }^{10}$ Increased Th17 cell activity was noted during T1R with simultaneous decrease in TGF- $\beta$ and increase in IL-6. ${ }^{11}$ Recently, it is reported that IL- 6 regulates the inflammatory responses in T1R patients by inducing the production of IL-17 from Th17 cells. ${ }^{12}$ Contradictory findings are recorded in the involvement of immune complexes, neutrophils and various immunological mediators during Type 2 reaction or Erythema nodosum leprosum (ENL). ${ }^{13}$ Many studies, including genetic evidence, suggest a significant role of innate immune responses in leprosy and during reactional complications. Mycobacterial cell wall components are known to induce proinflammatory responses in macrophages through TLR2 signalling. ${ }^{14}$ The active interaction between ligands and membrane bound receptors are effectively influenced by soluble receptors. ${ }^{15}$ The difference in the level of soluble receptors is noted to be associated with disease progression in HIV ${ }^{16}$ and TB. ${ }^{17,18}$ Soluble decoy TLRs were hypothesized to be potentially powerful competitors for TLR agonists. ${ }^{19}$ Serum soluble TLR2 has been explored as a novel potential disease biomarker for Multiple sclerosis. ${ }^{20}$ To the best of our knowledge, soluble TLR2 level is not explored in leprosy patients. Activation of TLR2 was linked to the expression and secretion of IL- $6 .{ }^{21}$ Nitric oxide (NO) is another important primary mediator of pathogen killing 22 which is produced by Nitric Oxide Synthase 2 (NOS2) enzymes by activated macrophages. ${ }^{23}$ During infection NOS2 expression is regulated by inflammatory cytokines. ${ }^{24}$ NOS2 expression was reported in lesions of borderline leprosy patients. ${ }^{25}$ Augmented urinary NO metabolites were also detected in leprosy reactional patients. ${ }^{26,27}$ The possible association of NOS2 gene polymorphism during reactional episodes in leprosy was reported earlier. ${ }^{28} \mathrm{It}$ has aslo been reported that nerve damage in leprosy occurs due to excessive production of nitric oxides by macrophages after induction with phenolic glycolipid of $M$ leprae. ${ }^{29}$ As serum or plasma is considered to be a suitable diagnostic specimen, exploring various soluble mediators warrants investigation. The aim of the present study is to analyse the profile of nitrite, sTLR2 
and IL-6 in serum samples of untreated leprosy patients, leprosy reactional patients and to compare these with healthy controls and non-reactional patients.

\section{Materials and methods ethics statement}

The protocol of this study was approved by the Institutional human ethics committee. This committee was formed as per the guidelines set by Indian Council of Medical Research. ${ }^{30}$ Written informed consent was obtained from all the study subjects.

\section{LEPROSY PATIENTS}

A total of 231 leprosy patients attending the OPD of NJIL and OMD, Agra, from 13 to 70 years of age were diagnosed clinically on the basis of skin patches, nerve thickening, sensation testing and bacteriologically by slit skin smear test. Patients were divided into a fivegroup spectrum according to the Indian Association of Leprologists. ${ }^{31}$ Initially paramedical workers (PMWs) examined all patients followed by re-evaluation by experienced clinicians. The Ridley-Jopling classification was validated histopathologically in sixty six representative patients. Reactions (ENL and RR) were diagnosed in patients as per the case definition described elsewhere. ${ }^{32}$ Cases suffering from HIV, TB, diabetes mellitus or any other immunosuppressive disorders were excluded.

\section{HEALTHY CONTACTS AND CONTROLS}

A total of 48 healthy subjects who accompanied the patients, and who were staying in the same locality and shared a similar societal and financial condition were considered as healthy contacts. The age of these contacts ranged from 14 to 65 years. Fifty-eight healthy controls were research scholars and short term project trainees and employees of our institute. Ages of these controls was between 7 and 57 years of age. Exclusion criteria for healthy individuals to participate included fever, viral infections, immunological diseases, and other illnesses, as well as any previous history of tuberculosis or leprosy, and current medication.

The details of study participants are described in Table 1.

\section{BLOOD SAMPLES}

Five $\mathrm{ml}$ of venous blood was collected aseptically by antecubital venepuncture in plain vials. These tubes were kept at room temperature for 30-60 minutes. Serum was separated from clotted blood by centrifuging at $1500 \mathrm{~g}$ for 10 minutes at $4{ }^{\circ} \mathrm{C}$ and stored in aliquots at $-80{ }^{\circ} \mathrm{C}$.

\section{MEASUREMENT OF SOLUBLE TOLL-LIKE RECEPTORS, NITRITE AND INTERLEUKIN 6}

STLR2 and IL-6 were estimated in all the samples using commercially available kits (Human DuoSet from R\&D, USA). Nitrite level was estimated in all samples by Griess colorimetric assay (Promega, USA). The concentration of nitrite, sTLR2 and IL-6 in plasma samples was calculated by the 4 Parameter Logistic curve fit graph drawn for standards.

\section{STATISTICAL ANALYSIS}

After quantification all observations were tabulated and analysed in Graph Pad Prism version 3.00 for Windows (Graph pad Software, San Diego, CA). The findings are represented as a box and whisker plot. Comparisons of the groups were performed using the nonparametric Mann-Whitney test. For all analyses $P<0.05$ was considered as significant. 
Table 1. Demographic and clinical details of the study groups

\begin{tabular}{cccccc}
\hline Participants & Numbers & Male & Female & Mean age \pm SD & $\begin{array}{c}\text { Duration of disease } \\
\text { in months }\end{array}$ \\
\hline $\begin{array}{c}\text { Leprosy affected persons } \\
\text { Leprosy Type }\end{array}$ & 231 & 140 & 91 & $35.2 \pm 13.2$ & $0-72$ \\
BT & 93 & 45 & 48 & $33.3 \pm 12.35$ & $0-60$ \\
BB & 48 & 32 & 16 & $38.7 \pm 15.64$ & $0-72$ \\
BL & 31 & 27 & 04 & $37.81 \pm 13.53$ & $0-36$ \\
LL & 59 & 36 & 23 & $33.9 \pm 11.93$ & $0-60$ \\
ENL/T2R & 29 & 18 & 11 & & $0-36$ \\
RR/T1R & & & & $33 \pm 10.71$ & $0-36$ \\
(LL, BL $=3)$ & 42 & 28 & 14 & $39.43 \pm 14.1$ & - \\
(BT $=11$, BB $=17$, BL $=14)$ & 48 & 42 & 06 & $40.7 \pm 14.88$ & - \\
Healthy contacts & 58 & 25 & 33 & $25.4 \pm 7.01$ & \\
Healthy controls & & & & & \\
\hline
\end{tabular}

BT-Borderline tuberculoid, BB-Midborderline, BL-Borderline leprosy, LL-Lepromatous leprosy, ENL/T2RErythema nodosum leprosum/Type 2 reaction, RR/T1R-Reversal reaction/ Type 1 reaction.

\section{Results}

Of 231 serum samples obtained from leprosy patients, 48 healthy contacts and 58 healthy controls, the following components were tested.

\section{ESTIMATION OF SERUM STLR2 IN LEPROSY PATIENTS, HEALTHY CONTROLS AND CON- TACTS}

Serum sTLR2 was measured in 104 leprosy patients, 36 healthy contacts and 44 healthy controls. The mean concentration of serum STLR2 was significantly higher in healthy controls $(29,050 \mathrm{pg} / \mathrm{ml})$ compared to leprosy patients $(5975 \mathrm{pg} / \mathrm{ml})$ ( $p$-value 0.0024$)$, which was in turn higher than the level in healthy contacts $(3878 \mathrm{pg} / \mathrm{ml})(p$-value 0.048$)$, as shown in Figure 1A.

\section{ESTIMATION OF SERUM STLR2 IN LEPROSY CASES WITH ENL AND NON-REACTIONAL} CASES

The level of serum sTLR2 was measured in 5 ENL patients and 20 non-reactional patients classified as either BL and LL. The mean concentration of sTLR2 exhibited no statistical difference between ENL patients $(7692 \mathrm{pg} / \mathrm{ml})$ and non-reactional patients $(7738 \mathrm{pg} / \mathrm{ml})(p$ value 0.7598 ) as shown in Figure $1 \mathrm{~B}$.

\section{ESTIMATION OF SERUM STLR2 IN LEPROSY CASES WITH RR AND NON-REACTIONAL CASES}

The level of serum sTLR2 was measured in 6 RR patients and 79 non-reactional patients classified as BT, BB or BL. The mean concentration of sTLR2 level in serum was higher but not statistically significant in patients with RR reactions $(7226 \mathrm{pg} / \mathrm{ml})$ compared to leprosy patients without reactions $(5502 \mathrm{pg} / \mathrm{ml})(p=0.2168)$ as shown in Figure 1C.

Serum nitrite level was measured in 6 tuberculoid, 32 borderline and 75 lepromatous leprosy patients, 40 healthy contacts and 15 healthy controls. The mean level of serum nitrite was compared among various clinical groups of leprosy patients and depicted in Table 2 and Figure 2A. 


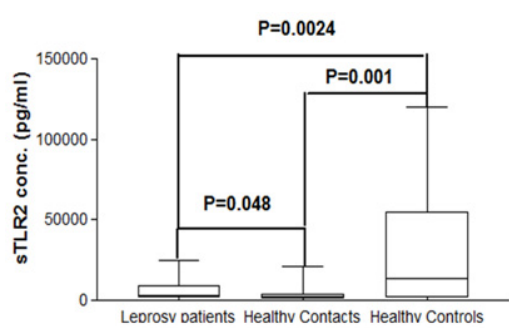

A

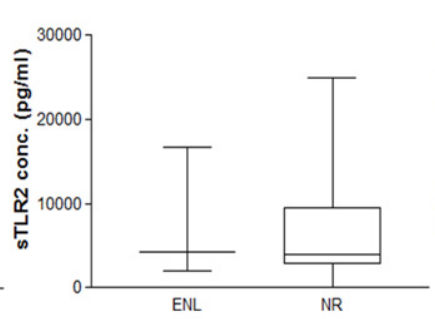

B

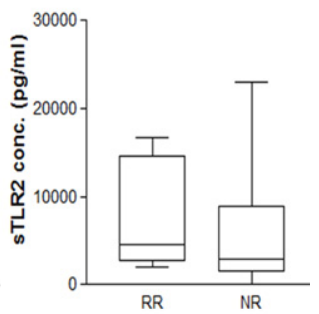

C

Figure 1 Level of serum soluble TLR2 in leprosy patients, healthy controls, and healthy contacts. The mean level of serum sTLR2 was measured by sandwich ELISA using DuoSet from R\&D System and represented in $\mathrm{pg} / \mathrm{ml}$. The serum level sTLR2 was represented as a box and whisker plot. Each box is with whiskers on both sides with upper and lower adjacent values respectively. The box shows the 75th, Median, and 25th percentile values from the upper hinge to the lower hinge respectively. Pairwise comparison was made by Mann-Whitney test and the $p$-value is represented on the top of the figure. A-sTLR2 level in leprosy patients (TT, BT, BB, BL, LL, $n=104$ ) healthy contacts $(n=36)$ and healthy controls, $(n=44)$, B- BL and LL leprosy patients with ENL $(n=5)$ and BL and LL patients without any reactional episodes (NR, $n=20)$ and C- BT, BB and BL leprosy patients with RR $(n=6)$ and $\mathrm{BT}, \mathrm{BB}$ and $\mathrm{BL}$ patients without any reaction $(\mathrm{NR}, n=79)$.

Table 2. Comparison of serum nitrite level between different clinical groups

\begin{tabular}{ccc}
\hline Study subjects & $\begin{array}{c}\text { Mean concentration of nitrite } \\
\text { in micromolar with SD }\end{array}$ & $P$-value \\
\hline Healthy Contacts $(n=40)$ & $19.23 \pm 16.79$ & $0.008^{*}$ \\
Healthy Controls $(n=15)$ & $14.34 \pm 22.34$ & $0.006^{\#}$ \\
Tuberculoid Leprosy (BT) $(n=06)$ & $26.59 \pm 29.19$ & \\
Lepromatous leprosy (BL and LL) $(n=75)$ & $12.80 \pm 9.159$ & \\
Borderline (BB) $(n=32)$ & $14.40 \pm 9.10$ & \\
\hline
\end{tabular}

${ }^{*}$ Compared between Healthy Contacts and Lepromatous group of leprosy patients.

\#Compared between Tuberculoid and lepromatous group of leprosy patients.

ESTIMATION OF SERUM NITRITE IN LEPROSY CASES WITH ENL AND NON-REACTIONAL CASES

Serum nitrite level was measured in 25 ENL patients and 33 non-reactional patients. The mean concentration of serum nitrite exhibited no statistical difference between ENL patients (11.16 \pm $8.23 \mu \mathrm{M})$ and non-reactional patients $(13.63 \pm 9.45 \mu \mathrm{M})(p=0.3845)$. The level is represented in Figure 2B.

\section{ESTIMATION OF SERUM NITRITE IN LEPROSY CASES WITH RR AND NON-REACTIONAL} CASES

Serum nitrite level was measured in $33 \mathrm{RR}$ patients and 33 non-reactional patients. The mean concentration of serum nitrite level exhibited no statistical difference between RR patients $(14.37 \pm 14.79 \mu \mathrm{M})$ and non-reactional patients $(16.36 \pm 9.71 \mu \mathrm{M})$ with $p$-value 0.1866 . The level is depicted in Figure 2C.

ESTIMATION OF SERUM IL-6 LEVEL IN LEPROSY PATIENTS AND HEALTHY CONTROLS

Serum IL-6 level was measured in 19 leprosy patients and 14 healthy controls. The mean serum concentration of IL-6 exhibited significant statistical difference between leprosy patients 


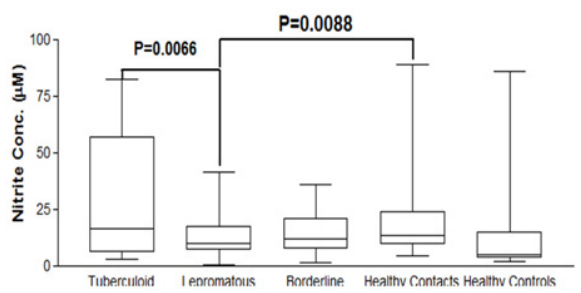

A

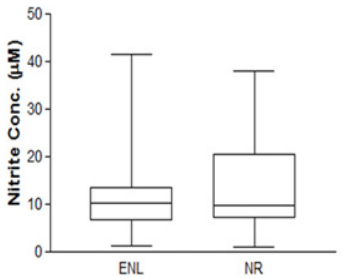

B

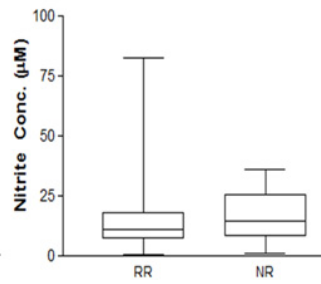

C

Figure 2 Level of serum nitrites in leprosy patients, healthy controls and healthy contacts. Mean levels of serum nitrites were measured using Griess's reagent and represented in micromoles. The serum nitrite levels were represented as box and whisker plots. Each box is with whiskers on both sides with upper and lower adjacent values respectively. The box shows the 75th, Median and 25th percentile values from upper hinge to lower hinge respectively. Pairwise comparison was made by Mann-Whitney test and $p$-value is represented on the top. of the figure. A-Nitrite level in Tuberculoid (BT, $n=6$ ) leprosy patients, Borderline leprosy $(\mathrm{BB}, n=32)$ patients, Lepromatous leprosy patients (BL and LL, $n=75)$, healthy contacts $(n=40)$ and healthy controls, $n=15, \mathrm{~B}-, \mathrm{BL}$ and LL leprosy patients with ENL $(n=25)$ and BL and LL patients without any reactional episodes $(\mathrm{NR}, n=35)$ and $\mathrm{C}-\mathrm{BT}, \mathrm{BB}$ and BL leprosy patients with $\mathrm{RR}(n=33)$ and BT, BB and BL patients without any reaction $(\mathrm{NR}, n=33)$.

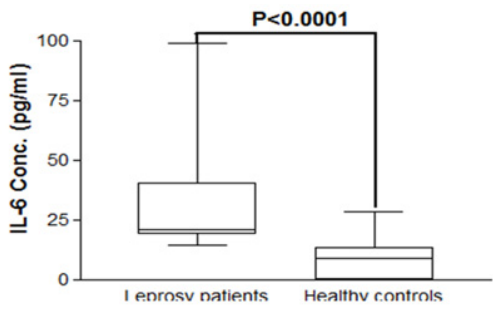

A

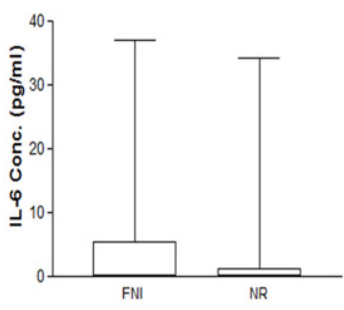

B

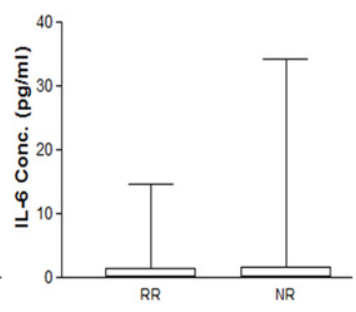

C

Figure 3 Level of serum IL-6 in leprosy patients and healthy controls. Mean level of serum IL-6 was measured by sandwich ELISA using DuoSet from the R\&D System and represented either in pg/ml. The serum level IL-6 was represented as a box and whisker plot. Each box is with whiskers on both sides with upper and lower adjacent values respectively. The box shows the 75th, Median, and 25th percentile values from the upper hinge to the lower hinge respectively. Pairwise comparison was made by Mann-Whitney test and the $p$-value is represented on the top of the figure. A IL-6 level in leprosy patients (BT, BB, BL, LL, $n=19)$ and healthy controls, $(n=14)$, B-, BL and LL leprosy patients with ENL $(n=12)$ and BL and LL patients without any reactional episodes $(\mathrm{NR}, n=18)$ and C-BT, $\mathrm{BB}$ and $\mathrm{BL}$ leprosy patients with RR $(n=12)$ and $\mathrm{BT}, \mathrm{BB}$ and $\mathrm{BL}$ patients without any reaction $(\mathrm{NR}, n=15)$.

$(31.48 \pm 22.22 \mathrm{pg} / \mathrm{ml})$ and healthy controls $(8.902 \pm 8.74 \mathrm{pg} / \mathrm{ml})$ with $(p$-value $<0.0001)$ as shown in Figure $3 \mathrm{~A}$.

\section{ESTIMATION OF SERUM IL-6 LEVEL IN LEPROSY CASES WITH ENL AND NON-REAC-} TIONAL CASES

Serum IL-6 level was measured in 12 ENL patients and 18 non-reactional patients. No statistical difference was found in serum IL-6 levels between ENL patients $(5.63 \pm 11.29$ $\mathrm{pg} / \mathrm{ml})$ and non-reactional patients $(2.76 \pm 8.17 \mathrm{pg} / \mathrm{ml})$ with $(p$-value 0.4847$)$ as shown in Figure 3B. 
ESTIMATION OF SERUM IL-6 LEVEL IN LEPROSY CASES WITH RR AND NON-REACTIONAL CASES

Serum IL-6 level was measured in 12 RR patients and 15 non-reactional patients. No statistical difference was found in serum IL-6 levels between RR patients $(2.01 \pm 4.33 \mathrm{pg} / \mathrm{ml})$ and nonreactional patients $(3.08 \pm 8.78 \mathrm{pg} / \mathrm{ml})$ with ( $p$-value 0.7327$)$ as shown in Figure $3 \mathrm{C}$.

\section{Discussion}

The present study explored the level of sTLR2 in leprosy for the first time to the best of our knowledge. Healthy controls were found to have higher levels of soluble TLR2 compared with leprosy patients and contacts of leprosy patients. Though the level of sTLR2 was higher in T1R patients compared to non-reactional counterparts, the difference was not statistically significant. Soluble TLR2 is reported to regulate the innate immune responses against invaders mediated through TLR2 signalling. ${ }^{33}$ Further, TLR 2 signalling has been shown to regulate the innate adaptive immune responses though various cytokines. ${ }^{34}$ Decreased levels in leprosy cases suggests lower immune activation during leprosy. Soluble TLR2 is reported to be associated with disease progression in HIV infection. ${ }^{16}$ Soluble TLR2 was noted to be present in breast milk, ${ }^{17}$ parotid saliva. ${ }^{35}$ Depletion of sTLR2 level was found in patients suffering from tuberculosis as compared to healthy controls, ${ }^{17}$ but another study showed an increased level of sTLR2 in pulmonary TB patients. ${ }^{18}$ Although higher expression of TLR2 was reported in tuberculoid leprosy patients compared to lepromatous leprosy patients, ${ }^{36}$ no report was available for soluble TLR2. Further investigation is needed to clarify the role of soluble TLR2 in leprosy reactions.

We observed higher concentration of serum nitrite in the tuberculoid group of leprosy patients and healthy contacts of leprosy patients compared to lepromatous leprosy patients. Earlier studies have suggested an increased level of serum nitrites in leprosy patients. ${ }^{37}$ Boga et al. noted an increased level of serum NOM in MB patients compared with healthy controls. ${ }^{38}$ Healthy contacts included in our study are residents of the same house/village or same geographical area as those of leprosy patients. Higher level of NO2 could be due to the responses to subclinical infection. This could be due to the initial attempts of host to resist the infection by producing higher level of nitric oxides. Follow up of these contacts would be interesting to monitor serum nitrite levels as a potential marker for disease progression. Increased production of NOS2 was reported in skin biopsies of Type 1 reactional patients compared to patients without reaction in Ethiopia. NOS2 production was found to be higher in patients with reversal reaction compared with non-reactional patients in skin biopsies. ${ }^{25}$ NOS2 was found to be higher in skin biopsies in Type 1 reaction $p<0.001 .{ }^{39}$ However, our observation in reactional patients was inconclusive. This could be due to an insufficient number of reactional patients or to undisclosed antireactional therapy taken by patients.

In our study, the mean level of IL-6 cytokine in leprosy patients was significantly higher than in the control group, indicating immune stimulation by $M$. leprae. We could not find any significant differences in the level of IL-6 in patients with reaction and without reaction. Belgaumkar et al. 2007 have also noted elevated levels of cytokines including IL-6 in leprosy patients compared to controls. ${ }^{40}$ Whereas Stefani et al. 2009 have noted an increased level of IL- 6 in patients with type 1 reaction. ${ }^{7}$ Possibly undeclared antireactional therapy taken by patients could have influenced the IL-6 level in our reactional subjects. 


\title{
Conclusion
}

The level of serum nitrite was observed to be higher in tuberculoid leprosy patients compared to lepromatous leprosy patients. The level was also higher in healthy contacts of leprosy patients compared to lepromatous leprosy patients. The sTLR2 level was significantly higher in healthy controls than leprosy patients and their healthy contacts. The level of IL-6 in serum was significantly higher in leprosy patients than in healthy controls $(p=0.001)$.

Specific authors contribution-KKM has conceived the idea and conceptualized the study. AD, RG, NA did experimental work, VS and SB helped in sample collection, HS, MA and RK did the clinical diagnosis and evaluation of study subjects, MN did the histopathological analysis, AD and RG wrote the manuscript, SAP, SSB and KKM reviewed and edited the manuscript.

\author{
Abbreviations \\ BB Borderline Borderline BL-Borderline lepromatous BT-Borderline tuberculoid \\ ENL Erythema nodosum leprosum IL-6 - Interleukin 6 \\ LL Lepromatous leprosy \\ M leprae Mycobacterium leprae \\ MB Multibacillary \\ NO Nitric Oxides \\ NOM Nitric oxide metabolites NOS-Nitric Oxide Synthase PB-Paucibacillary \\ RR Reversal reaction \\ STLR Soluble Toll like receptor T1R-Type 1 reaction in leprosy T2R-Type 2 reaction in \\ leprosy TLR-Toll like receptor
}

\section{Acknowledgements}

Source of financial support in the form of grants - This study is a part of the project which was funded by extra mural grant from Indian Council for Medical Research, New Delhi (Ref. no. 5/ 8/3(2)/2010-ECD1). Part of this work was funded by intramural support from the Institute. Mr. Amit Dubey was financially supported as NET JRF and SRF grant by Council for Scientific and Industrial Research, New Delhi (Award Letter no. 09/830(0011)/2012-EMR-1). The funders have no competing interest in relation to this work.

We would like to thank all the patients and volunteers for their participation and support during sample collection. We also thank Mr. M. M. Alam, Mr. M. S. Tomar, Mr. Santosh Masih and Mr. Ravi Rawat for providing technical help.

\section{Conflicts of Interest}

The authors report no conflicts of interest.

\section{References}

1 Britton WJ, Lockwood DNJ. Leprosy Lancet, 2004; 363(9416): 1209-1219, https://doi.org/10.1016/S0140-67 36(0415952-7.

2 Ridley DS, Jopling WH. Classification of leprosy according to immunity: a five group system. Int J Lepr, 1966; 34(3): 255-273.

3 Becx-Bleumink M, Berhe D. Occurrence of reactions, their diagnosis and management in leprosy patients treated with multidrug therapy; experience in the leprosy control program of the All Africa Leprosy and Rehabilitation Training Center (ALERT) in Ethiopia. Int J Lepr Other Mycobact Dis, 1992; 60(2): 173-184. 
4 Kumar B, Dogra S, Kaur I. Epidemiological characteristics of Leprosy reactions: 15 years' experience from North India. Int J Lepr, 2004; 72(2): 125-133.

5 Geluk A, van Meijgaarden KE, Wilson L et al. Longitudinal immune responses and gene expression profiles in type 1 leprosy reactions. J Clin Immunol, 2014; 34(2): 245-255, doi:10.1007/s10875-013-9979-x.

6 Sarno EN, Grau GE, Vieira LMM et al. Serum levels of tumour necrosis factor-alpha and interleukin-1during leprosy reactional states. Clin Exp Immunol, 1991; 84(1): 103-108.

7 Stefani MM, Guerra JG, Lucia A et al. Potential plasma markers of type 1 and type 2 leprosy reactions: a preliminary report. BMC Infect Dis, 2009; 9(75): doi:10.1186/1471-2334-9-75.

8 Sousa ALM, Fava VM, Sampaio LH et al. Genetic and Immunological Evidence Implicates Interleukin 6 as a Susceptibility Gene for Leprosy Type 2 Reaction. J Infect Dis, 2012; 205(9): 1417-1424, doi:10.1093/infdis/jis208.

9 Sales-Marques C, Cardoso CC, Alvarado-Arnez LE et al. Genetic polymorphisms of the IL6 and NOD2 genes are risk factors for inflammatory reactions in leprosy. PLoS Negl Trop Dis, 2017; 11(7): e0005754, https://doi. org/10.1371/journal.pntd.0005754.

10 Yuniati R, Agusni I. IL-6 Levels in leprosy patients with reversal reactions. P J M H S, 2018; 12: 1340-1342.

11 Saini C, Siddiqui A, Ramesh V et al. Leprosy reactions show increased Th17 Cell activity and reduced FOXP3+ Tregs with concomitant decrease in TGF- $\beta$ and increase in IL-6. PLoS Negl Trop Dis, 2016; 10(4): e0004592, doi:10.1371/journal.pntd.0004592.

12 Saini C, Srivastava RK, Tarique M et al. Elevated IL-6R on CD4+ t cells promotes IL-6 driven Th17 cell responses in patients with T1R leprosy reactions. Sci Rep, 2020; 10: 15143, https://doi.org/10.1038/s41598-02 0-72148-7.

13 Polycarpou A, Walker SL, Lockwood DNJ. A systematic review of immunological studies of Erythema Nodosum Leprosum. Front Immunol, 2017; 8: 233, doi:10.3389/fimmu.2017.00233.

14 Underhill DM, Ozinski A, Smith KD et al. Toll-like receptor-2 mediates mycobacterial induced proinflammatory signaling in macrophages. Proc Nalt Acad Sci, 1999; 96(25): 14459-14463, doi:10.1073/pnas.96.25.14459.

15 Heaney ML, Golde DW. Soluble receptors in human diseases. J Leuk Biol, 1998; 64(2): 135-146, https://doi.o rg/10.1002/jlb.64.2.135.

16 Heggelund L, Flo T, Berg K et al. Soluble toll like receptor 2 in HIV infection: association with disease progression. AIDS, 2004; 18(18): 437-439.

17 Lebouder E, Rey-Nores JE, Rushmere NK et al. Soluble forms of toll-like receptors (TLR) 2 capable of modulating TLR2 signaling are present in human plasma and breast milk. J Immunol, 2003; 171(12): 6680 6689, doi:10.4049/jimmunol.171.12.6680

18 Lara GAA, Nawal MU, Ahmed AM. Evaluation of TLR-2 sera levels in a sample of Iraqi pulmonary TB patients. Iraqi J Sci, 2018; 59(4B): 1973-1980, doi:10.24996/ijs.2018.59.4B.2.

19 Liew FY, Xu D, Brint EK et al. Negative regulation of Toll-like receptor-mediated immune responses. Nat Rev Immunol, 2005; 5: 446-458.

20 Hossain MJ, Morandi E, Tanasescu R et al. The soluble form of toll-like receptor 2 is elevated in serum of multiple sclerosis patients: a novel potential disease biomarker. Front. Immunol, 2018; 9: 457, doi:10.3389/fimmu.2018.00457

21 Flynn CM, Garbers Y, Lokau J et al. Activation of Toll-like Receptor 2 (TLR2) induces Interleukin-6 transsignaling. Sci Rep, 2019; 9: 7306, https://doi.org/10.1038/s41598-019-43617-5.

22 Bogdan C. Nitric oxide and the immune response. Nat Immunol, 2001; 2(10): 907-916, doi:10.1038/ni1001907.

23 Nathan C. Nitric oxide as a secretory product of mammalian cells. FASEB J, 1992; 6(12): 3051-3064, https://d oi.org/10.1096/fasebj.6.12.1381691.

24 Nathan C, Xie QW. Regulation of biosynthesis of nitric oxide. J Biol Chern, 1994; 269: 13725-13728.

25 Little D, Khanolkar-Young S, Coulthart A et al. Immunohistochemical analysis of cellular infiltrate and gamma interferon, interleukin-12, and inducible nitric oxide synthase expression in leprosy type 1 (reversal) reactions before and during prednisolone treatment. Infect Immun, 2001; 69(5): 3413-3417, doi:10.1128/IAI.69.5.34133417.2001 .

26 Schon T, Hernandez-Pando RH, Negesse Y et al. Expression of inducible nitric oxide synthase and nitrotyrosine in borderline leprosy lesions. Br J Dermatol, 2001; 145(5): 809-815, https://doi.org/10.1046/j.1365-2133.200 1.04491.x.

27 Mohanty KK, Gupta M, Girdhar B et al. Increased level of urinary nitric oxide metabolites in leprosy patients during type 2 reactions and decreased after antireactional therapy. Lep Rev, 2007; 78(4): 386-390.

28 Dubey A, Biswas SK, Sinha E et al. Association of nitric oxide synthase2 gene polymorphisms with leprosy reactions in northern Indian population. Infect Genet Evol, 2017; 51(July): 67-73, doi:10.1016/j.meegid.2017.03.015. 
29 Madigan CA, Cambier CJ, Kelly-Scumpia KM et al. A macrophage response to mycobacterium leprae phenolic glycolipid initiates nerve damage in leprosy. Cell, 2017; 170: 973-985, http://dx.doi.org/10.1016/j.cell.2017.0 7.030 .

30 Indian Council for Medical Research. Ethical guidelines for biomedical research on human participants 2006 http://icmr.nic.in. (Accessed 11.07.03).

31 IAL. Clinical histopathological and immunological features of the five type classification approved by the Indian Association of Leprologists. Lepr India, 1982; 54(1): 22-25.

32 Kar HK, Sharma P. Leprosy reactions. In: Kar HK, Kumar B (eds), IAL-text Book of Leprosy. New Delhi, India: Jaypee brothers Medical publishers (P) Ltd, 2010; pp. 269-289.

33 Harding CV, Boom WH. Regulation of antigen presentation by Mycobacterium tuberculosis: a role for toll-like receptors. Nat Rev Microbiol, 2010; 8(4): 296-307, doi:10.1038/nrmicro2321.

34 Akira S. TLR signaling. Curr Top Microbiol Immunol, 2006; 311(1): 1-16, doi:10.1007/3-540-32636-7_1.

35 Kuroishi T, Tanaka Y, Sakai A et al. Human parotid saliva contains soluble toll like receptor (TLR) 2 and modulates TLR2 mediated interleukin-8 production by monocytic cells. Mol Immunol, 2007; 44(8): 1969-1976, https://doi.org/10.1016/j.molimm.2006.09.028.

36 Krutzik SR, Tan B, Li H et al. TLR activation triggers the rapid differentiation of monocytes into macrophages and dendritic cells. Nat Med, 2005; 11(6): 653-660, doi:10.1038/nm1246.

37 Schalcher TR, Vieira JLF, Salgado CG et al. Antioxidant factors, nitric oxide levels, and cellular damage in leprosy patients. Rev Soc Bras Med Trop, 2013; 46(5): 645-649, doi:10.1590/0037-8682-1506-2013.

38 Boga P, Shetty VP, Khan Y. Nitric Oxide metabolites in sera of patients across the spectrum of leprosy. Indian J Lepr, 2010; 82(3): 123-129.

39 Lockwood DNJ, Suneeta L, Sagili KD et al. Cytokine and protein markers of Leprosy reactions in skin and nerves: baseline results for the North Indian INFIR cohort. PLoS Negl Trop Dis, 2011; 5(12): e1327, doi:10.1371/journal.pntd.0001327.

40 Belgaumkar VA, Gokhale NR, Mahajan PM et al. Circulating cytokine profiles in leprosy patients. Lepr Rev, 2007; 78(3): 223-230. 